6. Böttiger BW, Bernhard M, Knapp J, Nagele P. Influence of EMS-physician presence on survival after out-of-hospital cardiopulmonary resuscitation: systematic review and meta-analysis. Crit Care. 2016;20(1):4.

7. Avellanas ML. Atención al Accidentado en el medio natural. Guía de urgencias; 2009. EdikaMed SL. ISBN 978-84-7877$542-2$.

8. Caldarola P, Gulizia MM, Gabrielli D, Sicuro M, De Gennaro L, Giammaria M, et al. ANMCO/SIT Consensus Document: telemedicine for cardiovascular emergency networks. Eur Hear J Suppl. 2017;19(Suppl D):D229-D243.

9. Bøtker MT, Jacobsen L, Rudolph SS, Knudsen L. The role of point of care ultrasound in prehospital critical care: a systematic review. Scand J Trauma Resusc Emerg Med. 2018;26(1):51.

10. Poole K, Couper K, Smyth MA, Yeung J, Perkins GD. Mechanical CPR: Who? When? How? Crit Care. 2018;29;22(1):140.

\section{In Response to Impact of Half Dome Cable Permitting by Spano et al}

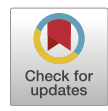

\section{To the Editor:}

We are writing this letter in response to an article published in Wilderness \& Environmental Medicine entitled "Impact of a Half Dome Cable Permitting Process on Search and Rescue Activity, Hiker Mortality Rates, and Operational Costs Above Little Yosemite Valley" (referred to hereafter as "the article"). ${ }^{1}$ We served as the principal investigators on the research conducted in Yosemite National Park to help inform the Half Dome Stewardship Plan and Half Dome cables permitting process. ${ }^{2-5}$ The purpose of our letter is to provide context that is missing from the article and reveals important issues in the research design, analysis, and conclusions presented. Our points are as follows:

1. The research presented in the article is based on the premise that the purpose of the Half Dome permit system is to "protect visitors in the wilderness" and, in turn, reduce the number and operational costs of search and rescue (SAR) incidents above the area of Yosemite National Park known as Little Yosemite Valley. In fact, the intent of the Half Dome permit system, with respect to safety, is simply to provide visitors with the opportunity to manage their own risk, specifically in the case of storm events where a rapid descent of the Half Dome cables might be necessary to avoid a lightning strike or wet conditions on the rock surface. ${ }^{6}$ Before the permit system, crowding during busy periods on the Half Dome cables and summit impeded visitors' ability to descend the cables freely. ${ }^{2}$ The National Park Service is clear in its public information regarding the Half Dome permit system and indicates that the permit system in no way guarantees visitors will be safe. ${ }^{7}$ In fact, the National Park Service clearly states in the Half Dome Stewardship Plan that challenge, risk, injury, and even death are inherent elements of wilderness. Consequently, the premise of the research and the corresponding statistical tests in the article are fundamentally misaligned with the intent and purpose of the Half Dome permit system. A suitable framework for evaluating the efficacy of the Half Dome permit system, with respect to its safety-related objectives, would be to compare the number of mass evacuations from the Half Dome summit and cables during storm events before and after the implementation of the permit system - or, similarly, to compare the number of people per event evacuated from the Half Dome summit and cables during storm events before and after the permit system went into effect. In either case, there would be significant limits to any statistical comparisons owing to the rare and stochastic occurrence of these events.

2. Relatedly, the analyses presented in the article include SAR incidents involving nausea and vomiting, lower extremity injuries, heat and dehydration, and snakebites. In fact, it is reported in the article that the top causes of SAR incidents in the study area (ie, above Little Yosemite Valley) during the pre- and postpermit analysis periods were medical illnesses, lower extremity injuries, lost persons, and vomiting. As noted, however, the intent of the Half Dome permit system, with respect to safety, is to reduce the number and scale of mass evacuations from Half Dome by eliminating the constraints of overcrowding on ability to self-evacuate during storm events and similar circumstances. The permit system was not designed to reduce the number of cases of vomiting, broken bones, or similar types of medical incidents. As such, the study design does not provide a suitable basis to assess the efficacy of the Half Dome permit system, with respect to its safety-related intent and purposes. The closest the study comes to the intent of the permit system is in the summary of 2 evacuations of multiple stranded visitors on the Half Dome summit and cables; only the case that occurred before the permit system had the characteristics of an event the Half Dome permit system was intended to address (41 witnesses to a fatal fall during a hailstorm were evacuated from Half Dome in 2009). In the evacuation event that occurred after the permit system was implemented, visitors were actually directed up to Half Dome as something of a safe haven and an evacuation point from a wildfire below Half Dome.

3. Similarly, the Half Dome permit system is narrowly scoped to manage the number of people only on the $146 \mathrm{~m}$ (480 ft) cables route and Half Dome summit. Yet, the analysis presented in the article is based on SAR incident data for all of the area of the park above Little Yosemite Valley, which is the most popular area in the Yosemite wilderness, is at the head of one of the 
most heavily visited trail corridors in the park, includes a large backcountry campground (Little Yosemite Valley campground), and is used by high volumes of visitors for a broad range of purposes other than hiking to and up the Half Dome cables. Thus, there is a significant disconnect between the geographic scope of the Half Dome permit system and the analysis area in the study; in turn, the study design lacks the characteristics of a properly controlled experiment. Furthermore, the permit system has had the effect of reducing peak-day visitor use levels on the Half Dome cables and summit, but it is not known whether annual use on the cables route and summit has increased or decreased since the permit system was implemented. It is also not known whether use increased or decreased in the rest of the study area during the analysis period. As a point of reference, parkwide visitation increased by nearly $15 \%$ from the prepermit analysis period (2005-2009) to the postpermit analysis period (2011-2015); it may be reasonable to assume use in the nonpermitted portion of the study area increased to a similar degree. In fact, use in the nonpermitted area above Little Yosemite Valley after the permit system was implemented may very well have increased to an even greater degree than parkwide visitation as a result of visitors being displaced from the Half Dome cables route to other trails and destinations within the very popular vicinity. In either case, there is no empirical basis to determine or even closely estimate the levels of use in the study area before and after the implementation of the permit system, which renders analyses and conclusions about relationships between use levels and numbers of SAR incidents in the study area intractable.

4. In addition to the issues noted regarding the premise and design of the research as a basis to evaluate the efficacy of the Half Dome permit system, the statistical test results presented in the article are based on very limited sample sizes. The statistics of focus for the analysis are the average annual number of SAR incidents, by incident type or category, before and after the permit system, each of which is computed based on a sample size of 5 observations. Yet, statistical significance is reported in the article without careful acknowledgement of the very limited data on which these analyses are based and the important caveats that go with that. In fact, the findings of no significant differences for most of the statistical tests reported are likely to be a function of the lack of precision of the point estimates based on sample sizes of 5 , rather than there being no true differences in the means. At a minimum, a discussion of substantive versus significant differences is warranted. For example, concluding statements report no significant decrease in the cost of SAR incidents after the permit system was implemented, despite the fact that average annual costs were $\$ 44,582$ before the permit system and $\$ 27,027$ after. Similarly, there were half as many fatalities in the postpermit analysis period compared to the prepermit analysis period and no fatalities at all in 3 of the 5 years of the postpermit analysis period versus 1 or more fatalities in the study area in every year of the prepermit analysis period. Yet, the study concludes that the permit system has not reduced mortality. These and similar statistical test results are misconstrued in the article as providing evidence that the safety-related premise of the Half Dome permit system is flawed, when in fact the descriptive data presented in the study do not support this conclusion.

5. The most important point concerning the research presented in the article is with respect to the reporting and interpretation of results regarding the number of incidents in what is referred to as the "permit area." Despite the very small sample sizes used in the analyses, a significant difference was detected in the number of incidents in the "permit area," with more incidents reported after the permit system (20 incidents) than before the permit system (18 incidents). Naturally, this finding is counterintuitive and correspondingly worthy of attention; it is interpreted in the article to suggest that "use of permits appears to have increased the individual risk for a SAR incident in the permit area" equivalent to a "doubling of relative risk." The study further concludes that additional research is warranted to evaluate whether limiting use on the Half Dome cables has detrimental safety-related effects for permit holders. Discussion in the article suggests that the statistically significant increase in incidents in the "permit area" may be because the permit system has made the general public more aware of the Half Dome hike and that this may have had the unintended effect of drawing more unprepared (and therefore more susceptible to incidents) hikers to Half Dome. This potential explanation is unlikely, however, for at least 2 important reasons. First, the Half Dome hike has historically been one of the most iconic, advertised, and popular hikes in all of the US National Park System, attracting both skilled and unprepared hikers in large numbers. Results from the research we conducted before the Half Dome permit system provide empirical evidence of the degree to which many visitors were arguably unprepared for the Half Dome hike. ${ }^{2}$ The permit system now requires Half Dome hikers to plan in advance to apply for a permit, and those who receive a permit are provided with information about hiker preparedness with their permit and at the subdome where their permits are checked. Before the permit system, visitors could decide on the spur of the moment to hike the trail and were not directly provided any information about the challenges, risks, and preparedness required for the hike. Second, and most 
importantly, although there was no regular or even frequent ranger presence in the "permit area" before the permit system, since the permit system was implemented a ranger is stationed in the "permit area" on most days throughout the entire visitor use season to check permits and provide information about weather conditions and related factors. As noted in the article, the SAR incidents used in the analysis are recorded by rangers; correspondingly, the very means by which SAR incidents are recorded (ie, measured) have only been regularly present in the "permit area" since the permit system was implemented. This dramatically increases the likelihood of SAR incidents being recorded in the "permit area" during the postpermit analysis period compared to the prepermit analysis period, particularly for the most common types of SAR incidents found in the study, such as nausea, vomiting, and injuries that might otherwise not require a SAR response or be reported to park officials. Thus, the pre- and postpermit implementation comparison for the "permit area" is fatally flawed; it is analogous to measuring the number of speeding violations on a section of road before and after stationing a patrol car in the area to measure vehicle speeds. Unfortunately, the popular press has taken hold of the study results regarding the number of incidents in the permit area and reported that the Half Dome permit system has not made visitors safer, but rather the opposite. ${ }^{8}$

The points presented here regarding the research design, analysis, and conclusions presented in the article are critically important to note as the US National Park System and other protected natural areas around the globe continue to face unprecedented increases in visitation and associated impacts on park resources, visitor experiences, and public safety. ${ }^{9}$ The research and conclusions presented in the article are misleading in terms of their implications for the role of permit systems - and visitor use management more generally - in protecting the cherished landscapes and experiences managed by the US National Park Service and similar agencies around the world. The importance of this issue is underscored by recent articles about crowding-related safety issues and fatalities on the summit of Mount Everest ${ }^{10,11}$ and recent research and planning efforts to address related issues on the Angels Landing Trail in Zion National Park. ${ }^{12}$

Steven R. Lawson, $\mathrm{PhD}$ Resource Systems Group, Inc. (RSG), White River Junction, Vermont

Peter Newman, PhD The Pennsylvania State University, State College, Pennsylvania

\section{References}

1. Spano SJ, Seymer JA, Crane DH, Auerbach PS. Impact of a Half Dome cable permitting process on search and rescue activity, hiker mortality rates, and operational costs above Little Yosemite Valley. Wilderness Environ Med. 2019;30(2):113-120.

2. Lawson S, Choi J, Reigner N, Newman P, Gibson A. Half Dome Cables Modeling and Visitor Use Estimation Final Report: Yosemite National Park. White River Junction, VT: Resource Systems Group, Inc. (RSG); 2009.

3. Lawson S, Kiser B, Reigner N. Half Dome Cables Visitor Use Model Scenario Analysis Final Report: Yosemite National Park. White River Junction, VT: Resource Systems Group, Inc. (RSG); 2011.

4. Reigner N, Lawson S, Meldrum B, Pettebone D, Newman P, Gibson A. Adaptive management of visitor use on Half Dome, an example of effectiveness. J Park Recreat Admi. 2012;30(3):64-78.

5. Pettebone D, Meldrum B, Leslie C, Lawson S, Newman P, Reigner $\mathrm{N}$, et al. A visitor use monitoring approach on the Half Dome cables to reduce crowding and inform park planning decisions in Yosemite National Park. Landsc Urban Plan. 2013;118:1-9.

6. National Park Service. Half Dome Stewardship Plan: Safety Issues. Available at: https://www.nps.gov/yose/learn/manage ment/upload/halfdome-safety.pdf. Accessed July 19, 2019.

7. National Park Service. Half Dome Stewardship Plan Environmental Assessment. Available at: https://parkplanning. nps.gov/document.cfm? parkID $=347 \&$ projectID $=29443 \&$ documentID=44771. Accessed July 19, 2019.

8. Yadron S. Yosemite permits aren't making Half Dome safer. Available at: https://www.outsideonline.com/2395465/ yosemite-permits-arent-making-half-dome-safer. Accessed July 19, 2019.

9. Dodds R, Butler RW, eds. Overtourism: Issues, Realities, and Solutions. Berlin: De Gruyter; 2019.

10. Schultz K, Gettleman J, Mashal M, Sharma B. "It was like a zoo." Death on an unruly, overcrowded Everest. Available at: https://www.nytimes.com/2019/05/26/world/asia/mounteverest-deaths.html. Accessed July 19, 2019.

11. Jenkins M. How to fix Everest. Available at: https://www. outsideonline.com/2398393/everest-problems-crowdingsolutions. Accessed July 19, 2019.

12. National Park Service. Zion National Park Visitor Use Management Plan Scoping Newsletter. Available at: https://parkplanning.nps.gov/document.cfm?parkID =113\& projectID $=58542 \&$ documentID $=75631$. Accessed July 19 , 2019.

\section{In Reply to Drs Lawson and Newman}

To the Editor:

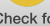

Check for
updates

We thank Drs Lawson and Newman for their letter. ${ }^{1} \mathrm{We}$ recognize your passion for safety. In this response, we address your critique of our work number by number and provide further commentary. To establish a baseline from 